\title{
Médiévales
}

Langues, Textes, Histoire

50 | printemps 2006

Sociétés nordiques en politique (XII ${ }^{\mathrm{e}}-\mathrm{XV}^{\mathrm{e}}$ siècles)

\section{Erikskrönika. Chronique d'Erik, première chronique rimée suédoise (première moitié du XIV siècle).}

Introduction, traduction et commentaires de Corinne Péneau, Paris, Publications de la Sorbonne, 2005, 260 p.

\section{Alban Gautier}

\section{CpenEdition}

\section{Journals}

Édition électronique

URL : https://journals.openedition.org/medievales/1413

DOI : $10.4000 /$ medievales. 1413

ISSN : $1777-5892$

Éditeur

Presses universitaires de Vincennes

\section{Édition imprimée}

Date de publication : 1 juin 2006

Pagination : 182-183

ISBN : 2-84292-186-0

ISSN : 0751-2708

Référence électronique

Alban Gautier, «Erikskrönika. Chronique d'Erik, première chronique rimée suédoise (première moitié du xı $v^{e}$ siècle). », Médiévales [En ligne], 50 I printemps 2006, mis en ligne le 09 février 2007, consulté le 22 avril 2022. URL : http://journals.openedition.org/medievales/1413; DOI : https://doi.org/10.4000/ medievales.1413

Ce document a été généré automatiquement le 22 avril 2022.

Tous droits réservés 


\section{Erikskrönika. Chronique d'Erik, première chronique rimée suédoise (première moitié du XIV siècle).}

Introduction, traduction et commentaires de Corinne Péneau, Paris, Publications de la Sorbonne, 2005, 260 p.

\section{Alban Gautier}

1 L'histoire de la Suède médiévale, peu connue en France, semble une longue succession d'usurpations, de luttes pour le pouvoir et de changements dynastiques. Or, dans cette histoire mouvementée, une période de stabilité se dégage: le règne des Folkungar, dynastie établie par le régent Birger Jarl, qui en 1250 fit élire roi son fils Valdemar. La Chronique d'Erik, récit de plus de 4500 vers composé entre 1322 et 1355 (datation établie avec soin, p. 29-34), rapporte l'histoire de cette dynastie jusqu'à l'avènement de Magnus Eriksson, son quatrième représentant, en 1319. L'ascension de Birger Jarl, puis la lutte entre Valdemar et son frère cadet Magnus Ladulås, qui le dépose en 1275, occupent les 1300 premiers vers. Le reste du récit est consacré au règne du troisième Folkung, Birger Magnusson, et à sa lutte contre ses cadets, les ducs Erik et Valdemar. La chronique, écrite sous le règne de Magnus, fils du duc Erik - qui donne son nom au poème -, épouse avec feu la cause des ducs. Elle se clôt avec la période mouvementée des années 1318-1320, qui vit successivement l'assassinat des ducs par leur frère le roi Birger, la révolte des partisans des ducs, la déposition et la fuite de Birger, la capture et l'exécution du jeune Magnus Birgersson, et l'élection de l'autre Magnus, alors âgé de quelques années (ces deux derniers événements, présentés dans cet ordre par la chronique, devant en réalité être inversés - inversion longuement et finement commentée par l'auteur).

2 La traduction de Corinne Péneau offre au public français l'accès à un texte majeur de la littérature et de l'histoire suédoises. Texte majeur pour plusieurs raisons, remarquablement présentées dans une longue et précieuse introduction d'une centaine de pages, qui fait ressortir tout l'intérêt de ce poème. «Vous souvenez-vous du coup de Håtuna? », demande le roi Birger au moment où il fait prisonniers ses frères. Cette 
phrase, passée à la postérité, est aujourd'hui connue de tous les Suédois. L'Erikskrönika est un monument de la mémoire nationale suédoise, une belle histoire de noblesse et de trahisons. Le poème, à mi-chemin du récit de fiction et de la chronique historique, est caractérisé par l'omniprésence du code chevaleresque. L'ère des Folkungar représente en effet la période de pénétration en Suède des codes littéraires et de comportement alors en vigueur dans l'ouest de la chrétienté. Capturer les ducs à l'issue d'un banquet, lieu de paix par excellence, constitue bien entendu une infraction de taille à ce code chevaleresque. Mais ce qui est pire, c'est que Birger les laisse mourir de faim dans leur cachot. Au contraire, les ducs et leurs partisans traitent leurs prisonniers de manière honorable. Un vers revient régulièrement dans le poème : « On ne le laissa pas mourir de faim ». Magnus Birgersson, capturé par les partisans de Magnus Eriksson, est traité de manière princière : il est certes exécuté, mais il est ensuite enseveli auprès de son grand-père Magnus Ladulås. Le topos du festin chevaleresque, très présent dans la chronique, est présenté dans l'introduction comme un lieu d'expression de la souveraineté, mais aussi de resserrement des liens à l'intérieur de la noblesse: le vocabulaire des récits arthuriens, parfois directement transposé du français ou de l'allemand, y est utilisé. Le poète, sans doute lui-même un chevalier, défend les nouvelles valeurs de sa caste, comme le montre son dénigrement de la valeur militaire des paysans (böndar). La chronique présente d'ailleurs un intérêt politique, et le poète plaide sans cesse pour une véritable monarchie élective : l'accession au trône de Birger, fils aîné de Magnus Ladulås, y est présentée comme une catastrophe; et, rétrospectivement, la déposition de Valdemar par Magnus Ladulås est interprétée comme un acte juste et dont la Suède profita.

3 Accompagnée d'une généalogie (indispensable, à laquelle on se réfère sans cesse), d'une carte (moins utile car trop peu précise), d'un glossaire (sommaire), et d'un index (noms de personnes uniquement), cette traduction comble un vide qui ne profitera pas qu'au lecteur français : c'est en effet la première traduction intégrale de ce texte dans une langue occidentale. 